Agro-Science Journal of Tropical Agriculture, Food, Environment and Extension Volume 13 Number 3 September 2014 pp. 30 - 36

ISSN III9-7455

\title{
GENETIC DIVERSITY BETWEEN LARGE WHITE AND NIGERIAN INDIGENOUS BREED OF SWINE USING POLYACRYLAMIDE GEL ELECTROPHORESIS (PAGE).
}

\author{
*Ndofor-Foleng H. M., Iloghalu, O. G., Onodugo, M. O., Ezekwe, A.G. \\ Department of Animal Science, University of Nigeria, Nsukka \\ *Corresponding author: harriet.ndoforfoleng @unn.edu.ng
}

\begin{abstract}
Sixty-two pigs (32 large white pigs and 32 Nigerian indigenous pigs were used in this study. Biochemical techniques were used in analyzing the blood serum samples obtained from the pigs using Polyacrylamide Gel Electrophoresis. A total of 14 loci were scored for the Nigerian Indigenous pigs and 10 for the Large White breed. The results of the molecular characterization with SDS-PAGE were analysed using PAST Package to determine genetic similarity coefficient and construct phylogenetic dendrogram. The within breed comparism of Nigerian indigenous pigs showed 62\% similarity while the Large White breeds showed $65 \%$ similarity. For the between-breed comparism, the Nigerian indigenous breeds and the Large White breeds were $48 \%$ similar. The moderate genetic similarity observed in the Nigerian indigenous pigs and the Large White pigs indicates a reasonable level of genetic dilution in both breeds.
\end{abstract}

Keywords: Electrophoresis, Genetic diversity, Pig, Polymorphism,

\section{INTRODUCTION}

Indigenous pigs have played an important role in smallholder farms and local populations for a long time (Mutua et al., 2011). In relation to biodiversity, local pigs seem to be losing its reservoir of genes that could be an asset for future use (Rangsun et al., 2013). In recent years, pig production in Nigeria has switched from local backyard systems to exotic industrialized production. The conservation of indigenous and exotic pigs in Nigeria as a genetic resource and vital components within the livestock sectorhave some challenges.

Genetic diversity is an asset for the future development of livestock production in Nigeria. The genetic characterization of local pigs in Nigeria should be the first step in considering the sustainable management or conservation of a particular population. Compared with the exotic pigs, the indigenous pigs have received very little research attention and are even in danger of extinction probably because of the little attention given to their characterization and research on genetic characterization is still at its rudimentary stage (Okeudo et al., 2007).

The genetic characterization of the domestic animals is part of the Food and Agricultural Organization global strategy for the management of farms (FAO, 2012). This strategy places a strong emphasis on the use of molecular methods to assist the conservation of endangered breeds and to determine the genetic status of breeds. Molecular markers have played some roles in the characterization of genetic diversity (Toro et al., 2006). Electrophoresis is one of the methods for the study of genetic diversity and has severally been used to establish the genetic distances among breeds and/or populations (Akinyemi et al., 2014).

Today, there is concern, on on the rate of extinction and disappearance of animal genetic resources (AnGR), thus, succeeding generation may inherit a narrow genetic base, unless present generation rise to the challenge (Vincent et al., 2014). Studies on genetics and preservation of indigenous breeds are crucial to the defining and

http://dx.doi.org/10.4314/as.v13i3.5 
registering of genetic resources. The genetic characterization of the Nigerian indigenous Pigs in the present study will provide a baseline data for the government and global programmes for the total conservation and preservation of Nigerian indigenous Pigs genetic resources. Therefore, this investigation was carried to evaluate the genetic diversity within and between breeds, in-addition to determining the genetic similarity between the Large White breed and the Nigerian indigenous breed using Polyacrylamide Gel Electrophoresis (PAGE).

\section{MATERIAL AND METHODS}

The experiment was carried out at the piggery unit, University of Nigeriab Teaching and Research farm Nsukka. Nsukka is in the derived savanna ecology on Longitudes $6{ }^{0} 25^{\mathrm{I}}$ and latitude $7^{\ominus} 24^{\mathrm{I}}$ at an altitude of $430 \mathrm{~m}$ above sea level. The climate is a humid tropical setting with a relative humidity range of $56.01-103.83 \%$. Average diurnal minimum temperature range between $22-$ $24.7^{\circ} \mathrm{c}$ while the average maximum temperature range between $33-37^{\circ} \mathrm{c}$ (Ndofor-Foleng et al., 2015). Annual rainfall ranges between 1680 $1700 \mathrm{~mm}$.

\section{The Parent Population}

The breeds of the pigs used for the study were the Nigerian indigenous Pigs and the Large White breed of swine. The local breeds were purchased from local pig farmers within the middle belt of Nigeria (Gboko) while the Large White breed was obtained from the piggery unit, University Of Nigeria Teaching and Research Farm. The pigs used were quarantined for one week to check and monitor their health conditions. They were also left to acclimatize before introducing them into the experimental units. Thirty-two non- pedigreed and unselected random bred males and females of the Nigerian indigenous pigs and Large White breed each formed the base population for the study.

\section{Management of Experimental Animals}

The selected parents which were gilt placed on 2.4 - 2.6kg quantity of feed especially for gilts which is the best strategy for maximization of litter size. They were allowed to get to full sexually maturity before the males were introduced into the breeding units at a ratio of 1 male : 3 females. After breeding, the animals were monitored till farrowing. The pregnant gilts were fed with a commercial diet of about $13-14 \%$ crude protein, $3400 \mathrm{k} \mathrm{cal} / \mathrm{kg}$ digestible energy according to Frank et al. (1995). The feed was increased in the first one to three days after farrowing with about $0.5 \mathrm{~kg} /$ day. Proper management and hygiene were ensured. Routine vaccinations were promptly carried out. After farrowing, data collection was made on individually basis.

\section{DNA Extraction and Genotyping Blood Sample Collection and Serum Preparation}

Blood for molecular typing was collected from each of the two breeds of pigs bred. This was achieved by means of 22 guage hypodermic needle. Three mls whole blood was withdrawn from either the tail vein or ear veins and diluted with $2 \mathrm{mls}$ saline water in a sample bottle. The two combinations was gently rocked before taking them to Classic Biomedical Laboratory within Nsukka town where it was left to stand for about 1hour before centrifugation at 2500rpm for 10minutes. After centrifugation, the serum/supernatants were collected using a micropipette in a separate $2 \mathrm{ml}$ tube and stored in the refrigerator before transporting to Biotechnological laboratory, Obafemi Awolowo University (OAU) inside a cooler packed with ice block which lasted until delivery for the analysis proper. The residual erythrocyte was discarded since haemolytic sera were not well separated. However, the samples were analysized as described by Adeleke et al. (2011). Protein polymorphisms were then analysized by sodium dodecyl sulphate-polyacrlamide gel electrophoresis (SDS-PAGE). Electrophoresis protocols were maintained throughout the analysis.

\section{Gel Preparation}

The preparation of the denaturing gel (SDSPAGE) was carried out. The composition of the gels were: 1.5 Tris-Hcl, $\mathrm{PH} 8.2$ (2.5ml) was dispensed into an Erlenmeyer flask, $4 \mathrm{ml}$ Acrylamide / Bis (30\%), 100 $\mu$ l SDS stock (10\% $\mathrm{w} / \mathrm{v}), 50 \mu \mathrm{l}$ Ammonium persulphate $(10 \%), 5 \mu \mathrm{l}$ tetramethylethylene diamine (TEMED) was all dissolved in $3.5 \mathrm{ml}$ distilled water for $10 \mathrm{ml}$ solution for the resolving gel. The electrophoretic kit was assembled and the first part of the gel (resolving gel) was done (Nowakowski et al., 2014). After which the comb were properly aligned in order for the wells to be properly formed. The surface of the gel was covered with distilled water during polymerization to smoothen the gel surface and mainly to expel air bubbles. After denaturing gel was the stacking gel. After proper polymerization of the two layer gels, it was later wrapped with nylon to prevent water from contaminating and it 
kept overnight in a fridge for proper preservation till the next day.

\section{Sample Preparation For SDS-PAGE}

Ten $\mu$ of the protein sample in a well labeled Effendorf of micro tubes was diluted with $40 \mu \mathrm{l}$ of sample buffer (SDS-reducing buffer) and was heated at about $95^{\circ} \mathrm{c}$ for 5 minutes in a water bath. The heated protein samples in the micro tube were later cooled for loading into the electrophoretic chambers already containing the stacked gel (below) and resolved gel (on top). In the electrophoretic chamber, there were 10 wells and each had the capacity to hold $15 \mu \mathrm{l}$ sample. For each serum/protein sample, $10 \mu \mathrm{l}$ of the cooled sample (serum + buffer solution) of each of the different breeds were loaded into the electrophoretic wells one after the other. The separation of protein was carried out with the aid of Bio-Rad electrophoretic power supply at 150milivolt in a running buffer (PH 8.3) 1 hour or a little more depending on the speed of migration of the sample (Thermo Fisher Scientific, 2010).

Coomasie-Blue Gel Staining For Sds-Page: After electrophoresis had been carried out, the gels were carefully removed or detached from loading chambers by placing it first inside the slightly diluted SDS reducing buffer to detach properly from the glass slides and it was left for some minutes before distilled water was further used for washing after which it was destained / fixed with staining solution (Coomasie-blue stain) for clarity of the protein bands. The gel was later scanned with a HP table scanner for future reference (Thermo Fisher Scientific, 2010).

\section{Statistical Analysis.}

Individual gels were placed under a light beam which allowed the bands to be seen clearly and were scored visually for presence (1) or absence (0) of protein bands (Ige et al., 2014). The position of the molecular weight marker assisted in scoring the protein bands on each gel. Data generated were subjected to statistical analysis using of PAST (Palentholgical statistics) to generate dendogram that measure genetic similarity.

\section{RESULTS AND DISCUSSION}

The SDS- PAGE gels scanned allowed the bands to be scored and the results displayed in plate 1 and 2. Plate 1 and 2 contains 10 lanes (1-10) each of different pig serum samples obtained from large white breed and Nigerian indigenous breed. The gels obtained from each of the population do not differ distinctively from each other. The results of the band counting were subjected to statistical analysis using PAST package (Palenthological Statistics) to draw dendogram (Figs 1 and 2) which measures genetic diversity within the population. Genetic diversity refers to the total number of genetic characteristics in the genetic makeup of the two breeds of pigs. It serves as a way for populations to adapt to changing environments (Zhang and Graham, 2011).

The dendrogram of all the pig population sampled showed a moderate level of genetic similarity (fig 1 and 2). This moderate genetic variation indicated that the population is not under the influence of natural selection. The importance is that the population is losing its high genetic variation which is sometimes referred to as heterozygousity (Amos and Balmford , 2001); which is a measure of the populations' ability to adapt to environmental changes and stress and thereby enabling them to survive in the same condition (Ige et al., 2014). The dendrogram of the pig sample from the large white population showed 2 major clusters A \& B (fig.1) and indicated a genetic similarity of $65 \%$ among some of the population sampled. On the other hand, $100 \%$ similarity was found among some of the Large White pigs. This is an indication that some of the Large White pigs are adequately protected from impurities or external influences which affects its genetic composition.

The dendrogram (Fig 2) of the Nigerian local pig indicated a genetic similarity of $62 \%$ among the population sampled. The highest similarity index observed among the pig population was $92 \%$ while the lowest was $42 \%$. From the genetic distances using UPGMA, the dendrogram obtained for the populations of all the pigs indicate a relatively moderate genetic similarity (62-65\%) which compared favorably with the results obtained from microsatellite DNA markers analysis in korean and Chinese Native pigs (Kim and Choi, 2002, Yang et al., 2003) as well as the results obtained from characterization of indigenous pigs in South Western Nigeria using blood protein polymorphism for pigs sampled from 4 locations (Akinyem et al., 2014). 


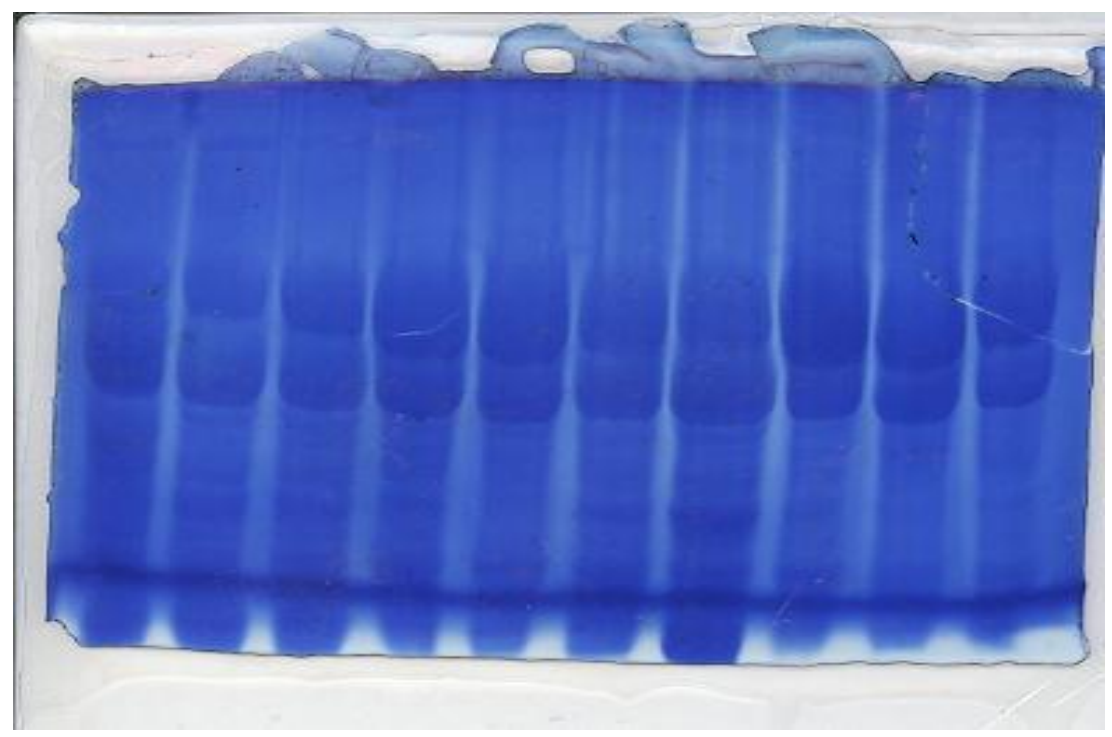

Plate 1: 10 lanes of different pig serum samples obtained from large white pigs

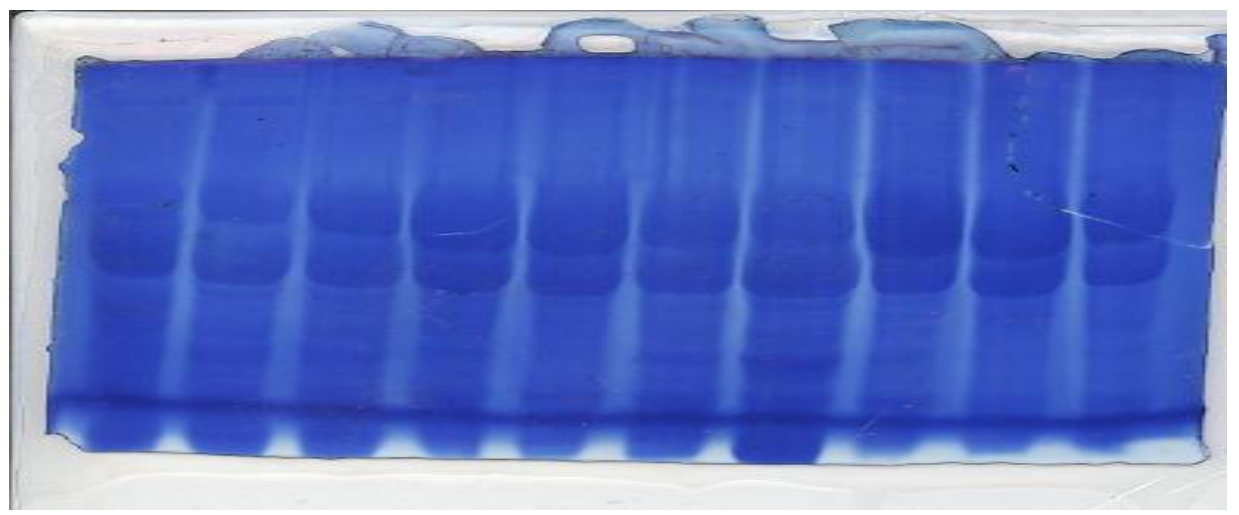

Plate 2: 10 lanes of different pig serum samples obtained from Nigerian indigenous breeds

The genetic distance among these populations should vary reflecting the differences in domestication model and history in the two breeds. However, this was not the case in this study, as the average genetic distance in large white populations was slightly higher than that in the Nigerian indigenous populations. High genetic variation is very important in pig management ( Adeola and Omitogun, 2012). This kind of baseline information on the genetic relatedness among genetic resources of Nigerian indigenous pigs is useful for designing a breeding programme as well as conservation. This result obtained in this study is not surprising as Zhang and Graham (2011) reported that the average heterozygosity was lower in pig than in human and other livestock. Domestic animal diversity is unique and cannot be replaced. As a matter of fact, biotechnology may attempt to improve breeds but not to replace loss of diversity. Biotechnological study can only detect loss of genetic diversity faster but will not be able to regenerate diversity if it is lost (Ige et al., 2014). 


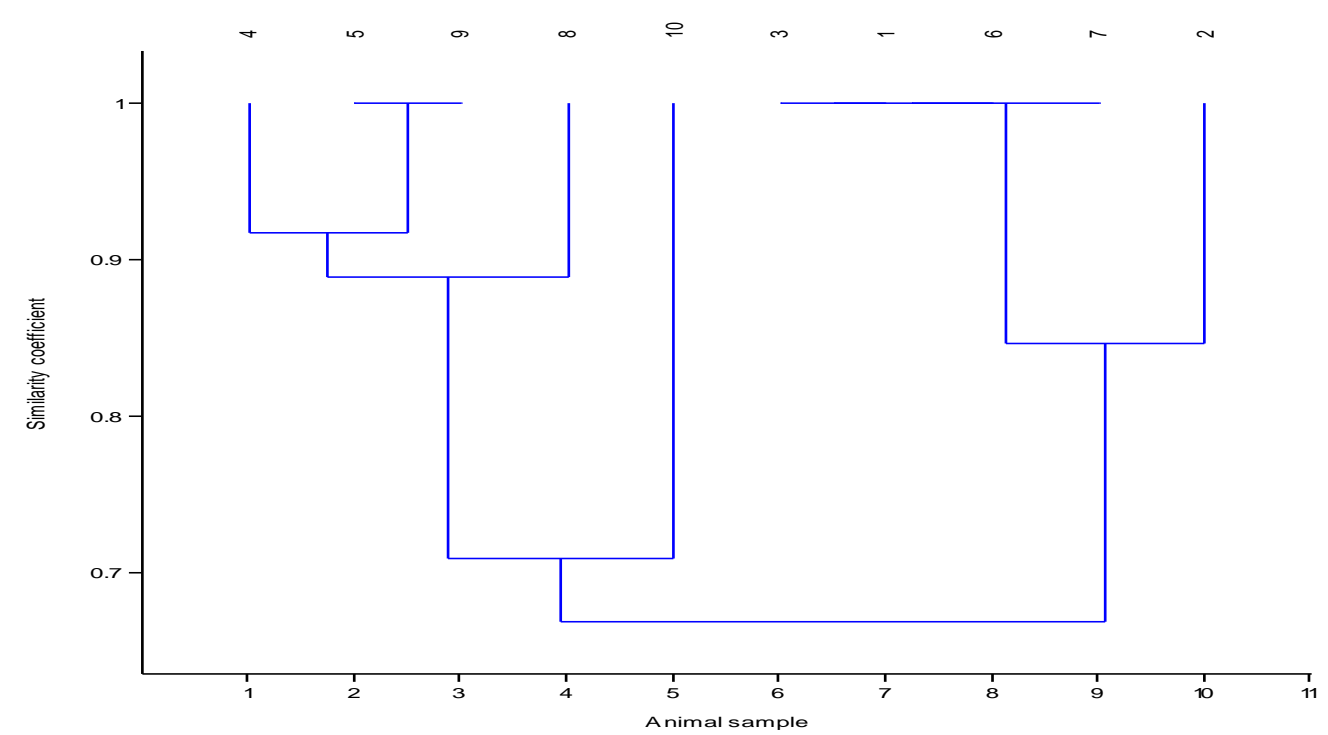

Fig. 1: Dendrogram for Exotic Large White Population

$1,2,34,5,6,7,8,9,10 \quad$ denotes animals sampled

$0.7,0.8 \ldots$ denotes similarity coefficient

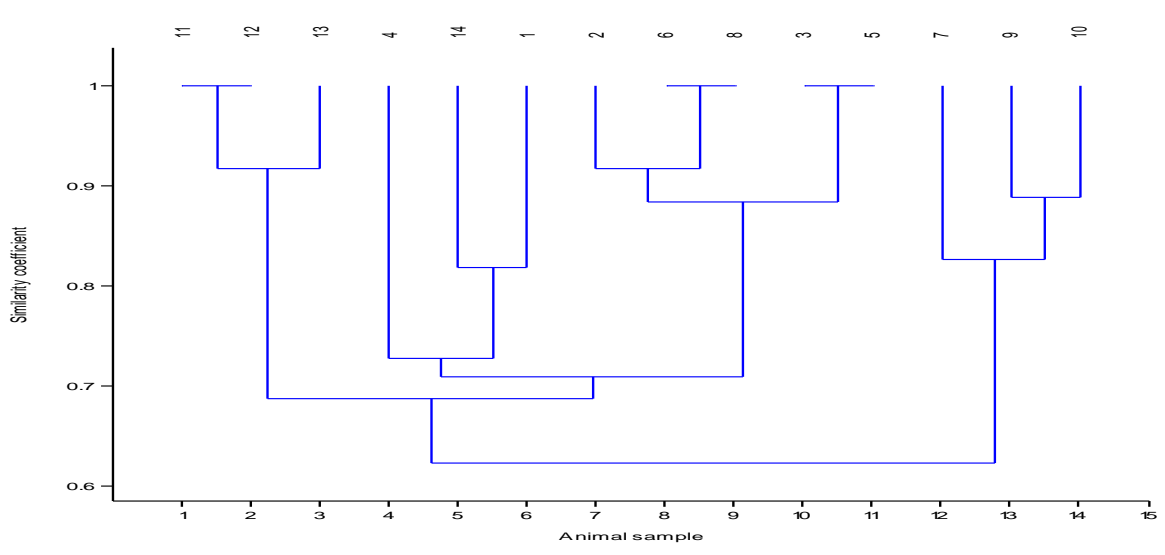

Fig. 2: Dendrogram for Nigeriaan indigenous pig population

$1,2,3 \ldots$ denotes animals sampled

$0.7,0.8 \ldots$ denotes similarity coefficient 
Table 1: Summary of genetic similarities within and between the two pig populations studied

\begin{tabular}{|l|l|l|}
\hline & Large white Exotic breeds & Nigerian indigenous breeds \\
\hline Large white Exotic breeds & 0.65 & \\
\hline Nigerian indigenous breeds & 0.48 & 0.62 \\
\hline
\end{tabular}

Values at the diagonal are the similarity coefficients of the populations studied

The Nigerian indigenous pigs from Gboko, Benue state though with relatively high geneticsimilarity are found to be diluted with the exotic breeds owning to the fact they are allowed to roam about, scavenge and fend for themselves. The Nigerian indigenous Pigs may go into extinction due to genetic dilution. There is need for proper conservation of indigenous stock for upgrading having in mind their good potentials like high survivability, disease resistance, heat tolerance etc. which will invariably increase pork availability even to the moderate populace and at the end increase and improve protein availability of common Nigeria.

\section{CONCLUSION}

The present result shows that there is uncontrolled interbreeding among pig breeds in some areas in Nigeria. This has lead to the narrowing of the gene pool, to render previous selection efforts futile. However a large sample is required so as to be able to monitor gene flow in a population in future. However, Pig genomic diversity within populations is quite variable.

From the gel electrophoretic profiles obtained using SPS- PAGE of serum proteins, there appears to be high level of genetic similarity on both breeds. For the Large White obtained from the University Farm, there is moderate level of cross breeding between the commercial lines available (leading to genetic dilution) in the farm. As a result of very moderate genetic similarity obtained between the Nigerian indigenous pigs, it could be concluded that there is an urgent need for genetic conservation of the local pigs in Nigeria to avert indiscriminate breeding which might end up in genetic erosion. The use of SDS-PAGE in analysizing protein polymorphism from pig blood samples is a tool for assessing genetic diversity and genetic status of unknown populations, but needs to be confirmed with more genetic loci as isozymes or hypervariable satellite DNA.

\section{REFERENCES}

Adeleke, M. A. Peters, S. O., Ozoje, M. O., Ikeobi, C. O. N., Adebambo, A. O., Olowofeso, O., Bamgbose, A. M. and Adebambo, O. A. (2011). A preliminary screening of genetic lineage of Nigerian Local Chickens based on blood protein polymorphisms. Animal Genetic Resources, 48: 23 - 28.

Adeola, A. C. and Omitogun, O.G. (2012). Characterization of indigenous pig in southwestern Nigeria using blood protein polymorphism. Animal Genetic Resource, 51:125-130.

Akinyemi,

Mabel Omolara

Temitope Matthew Adeoti

Alaba Jimoh Yunusa (2014). Blood

Protein Polymorphism of Local Pig in

Southwest Nigeria. Animal Molecular Breeding, 2014, Vol. 4, No. 2.

Amos William and Balmford Andrew (2001). When does conservation genetics matter? Heredity (2001) 87: 257-265; doi:10.1046/j.1365-2540.2001.00940.x

Food and Agric. Organization of the United Nation, 2012.

Frank Siewerdt, Ricardo A.C. and Valmircosta da Rosa (1995).Genetic parameters of litter traits in ree pig breeds in southern Brazil. Brazil J. Genetic. Rev. 18: 2, 199-205.

Ige, A.O., Salako, A.E., Akinyemi,M.O. Adedeji, T.A. Ojedapo, 1 L.O. and Oyelade, R.T (2014).Genetic Similarity of Yoruba Ecotype Indigenous Chickens Using Polyacrylamide Gel Electrophoresis. Journal of Biology, Agriculture and Healthcare www.iiste.org ISSN 22243208 (Paper) ISSN 2225-093X (Online) .4 .(6): 20155.

Kim, K. S. and Choi, C. B. (2002). Genetic structures of Korean native Pigs using microsatellite markers. Korean Journal Genetics, 24: 1 - 7 . 
$\mathrm{Ml}$ Ndofor-Foleng H. M., Iloghalu, O. G., Onodugo, M. O., Ezekwe, A.G.

Schelling, E (2011). Indigenous pig management practices in rural villages of Western Kenya. Livestock Research for Rural Development. 23 (7).

Ndofor-Foleng H. M., Ngongeh, L.A., Okolie, N. P. \& Okoli, E. L.(2015). Comparative study of growth traits and haematological parameters of Anak and Nigerian heavy ecotype chickens fed with graded levels of mango seed kernel (Mangifera indica) meal. Tropical Animal Health and Production. Vol 47 number 4. DOI 10.1007/s11250-015-0837-0.

Nei, M. (1972). Genetic distance between populations. The Amer. Naturalist. 106: $283-292$.

Nowakowski, A. B., Wobig, W.J and Petering, D.H (2014). Native SDS-PAGE: high resolution electrophoretic separation of proteins with retention of native properties including bound metal ions. Metallomics. 6(5): 68-78.10 doi: $10.1039 / \mathrm{c} 4 \mathrm{mt} 00033 \mathrm{a}$.

Okeudo, N.J., Aladi, N.O Okoli, I.C. and Akanno, E.C. (2007). Comparative Study of the Growth and Carcass Characteristics of the Nigerian Indigenous and Large White Pigs. Asian Journal of Animal Sciences, 1: $57-66$

Rangsun C., Christoph K. , Bertram B. and Kesinee G. (2013). Thai pigs and cattle production, genetic diversity of livestock and strategies for preserving animal genetic resources. Maejo International Journal of Science and Technology. 7(01), 113-132.
Ihermo Fisher Scientific Inc (2010). Thermo Scientific Pierce Electrophoresis Technical Handbook Featuring Thermo Scientific GelCode Staining Kits. Pp 15-

Toro, M. A., Fernández, J. and Caballero, A. (2006). Scientific basis for policies in conservation of farm animal genetic resources. Proc. 8th World Congr. Genet. Appl. Livest. Prod., Belo Horizonte, Brazil [CD-ROM ed.]. 8th WCGALP Secretariat, Belo Horizonte, MG, Brazil.

Vincent S. T., Momoh O. M. and Yakubu A (2014). Community-Based Management of Animal Genetic Resources (AnGR): Constraints and Prospects of AnGR Conservation in the Tropics (2014). J. Anim. Sci. Adv. 4(1): 624-6.

Yang, J., Wang, J., Kijas, J., Liu, B., Han, H., Yu, M., Yang, H., Zhao, S. \& Li, K. (2003), "Genetic diversity present within the near-complete mtDNA genome of 17 breeds of indigenous Chinese pigs", Journal of Heredity, vol. 94, no. 5, pp. 381-385.

Zhang C. and Graham Plastow (2011). Genomic Diversity in Pig (Sus scrofa) and its Comparison with Human and other Livestock. Curr Genomics. 12(2): 138146. 